\title{
Preparedness of Graduate-Teachers from the University of Trinidad and Tobago for the Real Classroom
}

\author{
Ms Marlene Thomas, Dr. Leela Ramsook \\ Centre for Education Programmes, The University of Trinidad and Tobago, Trinidad and Tobago, Valsayn \\ Campus, Trinidad and Tobago
}

*Corresponding Author: Ms Marlene Thomas, Centre for Education Programmes, the University of Trinidad and Tobago, Trinidad and Tobago, Valsayn Campus, Trinidad and Tobago

\begin{abstract}
Graduates with a Bachelor of Education (B.Ed.) degree from the University of Trinidad and Tobago (UTT) are currently employed at primary schools. The purpose of this study was to evaluate the extent to which graduate-teachers have been prepared for the real classroom. The study investigated beliefs about their preparedness, experiences and mitigating factors. A mixed method study was conducted with a sample of sixty participants. Data collection included face to face interviews, focus group interviews, questionnaires, and journaling. Findings revealed that graduate-teachers believed that they were prepared for the ideal classroom and that some courses should be modified. The themes include 1. Equipped with Competency 2. Complexity of the Classroom 3. Pragmatic Applications for Challenges 4. Inclusive Practice in Action. The research suggests modification of UTT's B.Ed. programme and perhaps other similar programmes to make teacher preparation more functionally appropriate for classroom practice. A period of internship is recommended.
\end{abstract}

Keywords: Graduate teachers; beliefs; experiences; themes

\section{INTRODUCTION}

Trinidad and Tobago is the most southerly isle of the archipelago of the Caribbean islands which has a population of approximately 1.3 million people. Education is available to all from pre-school to tertiary level both by the state and private providers. Prior to 2006, teacher education was prescribed for in-service teachers at teachers' colleges, by the Ministry of Education (MOE). However, the inservice system ended in 2006 and was replaced with pre-service teacher education provided by the national university, the University of Trinidad and Tobago (UTT). Since then, hundreds of teachers have graduated with a Bachelor of Education (B.Ed.) degree from the institution. These graduateteachers were subsequently assessed and hired by the MOE at various primary schools in the country. The graduate-teachers have been exposed to various theoretical and pedagogical courses. These included a practicum component every semester for a total period of twelve (12) weeks throughout the four year programme. This study seeks to fill a gap in the literature which demonstrates a perceived disparity between the institutional preparation of pre-service teachers for the practicum and the actual realities of classroom practice.

\section{PURPOSE OF THE STUdy}

The aim of the study is to examine the beliefs of graduate-teachers about their effectiveness or lack of effectiveness for the classes they now teach. It also seeks to investigate the factors that contributed to their efficiencies or inefficiencies. Also the study seeks to unearth the experiences of graduateteachers in the teaching of students in the real classroom now that they hold the responsibility for individual classes, having been exposed to the B.Ed. programme which included the practicum courses.

\section{REVIEW OF LITERATURE}

Generally, prospective teachers pursue courses in subject matter content, psychology of learning, pedagogy and classroom management. During the course of their programme, they practice in 
classrooms managed by cooperating teachers with whom they share the responsibility of classroom management and teaching. Upon completion of the programme, graduates seek teaching positions as teachers in schools managed by the MOE. Zmuda, Kuklis, and Kline (2004) question the gap between 'knowing' and 'doing' in the classroom. This study is informed by the theory of andragogy by Knowles, Holton and Swanson (2005) who postulated that adults are self-regulated, independent learners. Also Schön (1987) advocates that teachers need to engage in critical reflective practice for professional and self-development.

Ball (2000) is of the view that in most teacher preparation programmes, there exists a 'disconnect' between the theoretical and practical courses offered in the programmes and their linkages to the realities of daily classroom practice. However, Yost, Sentner and Forlenza-Bailey (2000) proffer that in the process of teacher preparation, the 'connections' are essential for future practice. The research is replete with examples of graduate-teachers as unique, bringing with them their individual learning and dispositions to the classroom. In spite of these differences, there are common strands in the teacher preparation programme which impact graduate-teachers in their daily practice.

With regard to teacher preparation, Cochran-Smith and Lytle (1999) divide the whole idea of teacher training into three categories, namely Knowledge for Practice, Knowledge in Practice and Knowledge of Practice. In the first category, Knowledge for Practice, the prospective teacher becomes the recipient of the expert knowledge of others for best practices. In assessing the prospective teacher in the field, the university lecturer focuses on the implementation of this expert knowledge. The second category, Knowledge in Practice, emphasizes learning to teach through experiences in the classroom and through the process of reflection upon one's practice with the aim of improving one's teaching. The third category merges intellectual learning with social learning and views knowledge as emergent. This idea for teacher training proposed by Cochran-Smith and Lytle (1999) may serve as a good guide for a total re-examination of the focus and mentoring process for undergraduates.

\section{RESEARCH QUESTIONS}

a. What are graduate-teachers' beliefs about their preparedness for the real classroom?

b. What factors led to the effectiveness/ lack of effectiveness of graduate-teachers in the real classroom?

c. What are graduate-teachers' experiences in the real classroom situation?

\section{SAMPLE}

The sample consisted of sixty participants who are currently teaching at various primary schools throughout Trinidad and Tobago. They are assigned to government or denominational schools which are funded by the MOE. The educational institutions which include boys' schools, girls' schools and co-educational schools are located in both rural areas and urban communities. A major commonality with the sample is that all participants graduated with the B.Ed. programme at UTT, the fully accredited national university in Trinidad and Tobago. Participants were therefore exposed to the same content, pedagogical knowledge and field practicum.

\section{Data Collection}

A mixed method study using both qualitative and quantitative data (Johnson \& Onwuegbuzie, 2004) was conducted. Purposive sampling was used to collect data from the sample. Participants were assured of anonymity, confidentiality of data and voluntary participation. Data were gathered using face to face interviews, focus group interviews, questionnaires and journaling. These multiple methods of data collection facilitated triangulation, which allows for "the richness and complexity of human behavior by studying it from more than one standpoint" (Cohen, Manion \& Morrison, 2011, p. 195). A questionnaire was administered to all participants after it was pilot tested to determine the suitability of items. Structured questions were used for focus group interviews which brought together graduate-teachers who had "similar attributes, experiences, or "focus" . . to surface the perspectives of the people" (Yin, 2016, p.336). Graduate-teachers also engaged in journaling based on their ongoing experiences in their respective classes.

\section{DATA ANALYSIS}

Data were analysed using a combination of quantitative statistical methods and qualitative procedures. The mixed method approach together with multiple methods of data collection allowed for credibility 
and "concurrent validity" (Cohen, Manion \& Morrison, 2011, p. 195). All interviews were audio taped and transcribed verbatim. Participants were asked to confirm the accuracy of the data which served to establish confirm ability and consistency in the data analysis process.

The data were read reiteratively in order to discern common ideas to form codes (Miles, Huberman \& Saldana, 2014). Categories and sub-categories were determined from the codes by reviewing the data repeatedly for commonalities, redundancies as well as outliers. Creswell (2012) suggests that the researcher should reduce overlap and redundancy of codes, categories and subcategories. The data were then crystallized into emergent themes. The method is comparable with approaches advocated by Lichtman (2006) and Miles, Huberman \& Saldana (2014).

\section{ReSUlts}

Ninety seven percent or fifty eight graduate-teachers believe that with the B.Ed. programme at UTT, they are "equipped with competency", which emerged as Theme 1. They believed that they were prepared with adequate pedagogical content knowledge for teaching at the primary level. They felt confident with content, au courant about theories and consider the programme to be effective and rigorous. But they indicated that there is a gap between the knowledge acquired and the reality of the classroom. The data revealed that $37 \%$ lamented that the training acquired is suited for the "ideal" classroom. Twenty eight percent (28\%) outlined that they were fully prepared; $33 \%$ were somewhat prepared, while $2 \%$ were unprepared.

Table1. Graduate-Teachers Beliefs about Their Preparedness

\begin{tabular}{|l|l|}
\hline Beliefs & Percentage (\%) \\
\hline Prepared for the ideal class & 37 \\
\hline Fully prepared for the real class & 28 \\
\hline Somewhat prepared for the real class & 33 \\
\hline Unprepared for the real class & 2 \\
\hline Total & 100 \\
\hline
\end{tabular}

Graduate-teachers complained that their practicum experiences may not be translatable into the real classroom situation because of the complexity of daily activities in their classes. Also, they added that cooperating teachers provided support during practicum whereas, as class teachers, they have to devise coping mechanisms on an individualized basis.

Graduate-teachers believe that by studying the numerous courses at UTT, they attained proficiency with content but bemoaned that the real experience of classroom management is very difficult. Twenty-nine (29) out of sixty (60) participants outlined that their classroom management skills are challenged as indiscipline has become the norm. As a result they are forced to compromise quality teaching time to deal with ongoing management issues. Fifteen (15) graduate-teachers felt that they were not adequately equipped to handle diversity as the school population is becoming increasingly varied. Twenty-one (21) cited the issue of special needs, as those students attend mainstream classes, except for severe cases, as mandated by the MOE. Fifty-six (56) identified a lack of counselling skills as a critical shortcoming.

Table2. Shortcomings Identified by Graduate-Teachers

\begin{tabular}{|l|l|}
\hline Descriptors & No of Participants (60) \\
\hline Classroom Management Skills & 29 \\
\hline Diversity Issues & 15 \\
\hline Special Needs Students & 21 \\
\hline Counselling Skills & 56 \\
\hline
\end{tabular}

It may be noted that counselling is not a course of study offered in the B.Ed. programme at UTT. Graduate-teachers emphasized that a great percentage of students have major problems, some of which may be attributed to reading problems, emotional concerns and dilemmas related to single parent families.

Graduate-teachers also delineated that other mitigating factors as well as the fluidity and complexity of daily classroom activities impede their efficiency and effectiveness. Out of sixty (60) participants, 31 revealed a lack of administrative support by principals; 24 little or no collegial support; 49 limited 
resources; 16 poor facilities; 25 limited access to technology; 18 the culture of the school; and 6 abusive parents.

Table3. Other Mitigating Factors in the Real Classroom

\begin{tabular}{|l|l|}
\hline Factors & No of Participants (60) \\
\hline Lack of support from administration & 31 \\
\hline Little or no collegial support & 24 \\
\hline Limited resources & 49 \\
\hline Poor facilities & 16 \\
\hline Limited access to technology & 25 \\
\hline The culture of the school & 18 \\
\hline Abusive parents & 6 \\
\hline
\end{tabular}

Other factors may contribute to the ineffectiveness of graduate-teachers. A non-supportive environment de-motivates enthusiastic graduate-teachers who are coerced to conform to the "culture" of the school. Their experiences included being admonished by colleagues as "new" teachers who are expected to have the answers to all problems. One participant explained, "In my class, I am able to identify exceptional learners at both ends of the spectrum ... the gifted and the slow learners ... We do not have the resources to deal with those challenges neither for those with learning disorders". But it must be noted that the graduate-teachers are not "master-teachers" but pre-service inductees, illequipped with teaching experience, except for the practicum exercise. Some of the activities which have been incorporated in the duties that graduate-teachers perform on a daily basis are outlined verbatim in italics below.

\section{DAILY NON-TEACHING ACTIVITIES OF GRAdUATE-TEACHERS}

1. Supervision of students- I supervise students from when they arrive on mornings and then for the entire day.

2. Assembly -I usually take the assembly twice per week.

3. Distribution of lunches - I am in charge of distributing lunches to the whole school and then individual teachers will look after their classes.

4. Departmental and staff meetings - . . the occurrence of too many staff meetings especially at short notice.

5. Meetings with parents - I meet regularly with parents, some of whom are abusive. It is disruptive and I feel unsettled.

One participant encapsulated other assigned tasks and crisis management succinctly: I also engage in several other assigned tasks. Each day, I attend to classroom duties such as delivering the curriculum, record keeping, and classroom management but I do so many different things - attend to children's physical mishaps, settle students' conflicts and counsel them about developing positive relationships. I look after sports, girl guides, Red Cross and inter-school competitions . . I I feel overwhelmed.

The themes that emanated include: 1. Equipped with Competency 2. Complexity of the Classroom 3. Pragmatic Applications for Challenges 4. Inclusive Practice in Action. Some experiences of participants, related to Theme 2: "Complexity of the Classroom", are outlined below.

6. The UTT programme made me confident. What was lacking was the understanding that 'teaching' extends far beyond the actual implementation of lessons. The teacher is required to fill many roles.

7. The classroom is replete with all kinds of problems and distractions and lessons seldom proceed in that kind of ideal, logical sequence. . . Practicum was an experience for me as I blossomed tremendously and learnt many theories.

8. The practicum needs to be shifted from this routine, mundane preparation and should connect the students in training for the reality of the classroom and society... I also engage in other tasks such as selling in the school cafeteria and distributing school lunches. 
9. The practicum in the teacher education curriculum did not prepare me for the realities of the classroom and the varieties of problems that I face on a daily basis, but I feel competent in terms of the content.

10. I believe that student teachers learn theory in teacher education courses but they do not connect it to the practicum. On reflection, I was introduced to the basics in lesson implementation while at UTT, but the real 'learning to teach' takes place in the classroom with all its challenges.

11. The practicum courses did not address the emotional and psychological issues which we have to deal with on a daily basis and I refer to issues such as effective counselling skills . . . Sometimes I am de-motivated and confused. Maybe, the practicum in the present teacher education curriculum should be re-structured to include an internship component in which both the school and the university should play an equally important role.

12. Although I pursued teacher preparation courses at UTT, I was not trained to handle students in a crisis, thus we need to focus on our needs and try to resolve them as far as possible among our own members. For example, I witnessed an incident when there was an earthquake.

Some selected journal extracts included below demonstrate Theme 3: "Pragmatic Applications for Challenges" or the need for rational interventions.

13. As the assembly comes to an end each morning, there is no idea of how the day will unfold. What may seem to be a normal morning could end on a dramatic note before the end of the day. For example, yesterday, during my lunch hour, a mother came to my class and asked to collect her daughter and younger sister because they had a medical appointment. She signed the necessary register and left with her two daughters. At the end of the school day, the father came to collect his daughters. Unknown to the teachers, he had been looking after the girls for the past two weeks because the mother had left during a domestic row. The social workers became involved in the domestic wrangle and made several visits to the school. During their visits to the school, in order to collect relevant information, they engaged the other implicated teacher and me in conversation during regular teaching hours. During these sessions, our classes were left unattended for a considerable period of time since there was never prior knowledge of their visits. These visits usually left me emotionally drained. First, I was unable to complete my daily schedule and secondly, I could not help but think of the two young girls who were not present at school since being taken by their mother.

14. Being in the classroom as a full time teacher I am faced with conflicts, fears, trials, pressures and stakeholder demands each day. I now hold a different view of education and teaching. In my former thinking, for me education meant getting my 'O' levels, then 'A' levels, and a degree. But now that thinking has changed. I believe that education should prepare an individual to become a constructive member of society. I must try to influence my students in a way that is constructive for themselves first, and also for society.

15. I am faced with content overload and multiple problems. Children learn at different rates and because I do not wish to leave any child behind, it is difficult to complete all the teaching content in any given term. It is over loaded and time span is too short for successful completion.

16. Other skills that the student-teachers need include effective counselling skills, conflict resolution, knowing the procedure to report a suspected case of incest to the Ministry of Social Development, and school violence in general. I see the co-operating teacher operating in the role of supporter and advisor. I think that the practicum needs to be revised with regard to the role of the cooperating teacher.

Some challenges that graduate-teachers faced are underscored in Theme 4: "Inclusive Practice in Action" are outlined below, indicating that reflection, differentiated instruction and inclusive practice are functional prerequisites for effective teaching and learning.

17. Diagnosis of needs - There is one student, Pete, who is visibly different. Whilst his body seems normal, he has an unusually small head, and engages in flapping movements with his arms like a bird in flight. He has never been given an official diagnosis ... I extend a comforting hand to him. 
18. Diverse needs - There are also many challenges. A major challenge is to plan and implement the most appropriate strategies to meet their (students') needs.

19. Slow learners - Because the children are slow learners, I must give added instructions ... I need to give individual assistance to many ... but the preparation is tremendous.

20. Disabilities -They have different kinds of disabilities. Their disabilities differ so much that I always have to keep looking for new ideas, new methods.

21. Parents - A critical problem is the lack of co-operation of parents to follow up on activities at home. As a result, there is no continuity with the activities that I implement.

22. Time - Time is also a major challenge. There is never enough time to get everything done. The other challenge is getting the right intervention with a particular student.

\section{DISCUSSION AND IMPLICATIONS}

The study revealed that some problems with graduate-teachers' preparedness may be considered 'structural' (emphasis on increase in intake and performance); 'national' (training for administrators); or may be related to the individual (classroom management skills). These are consistent with the findings of Wikan and Bugge (2014) in a study conducted in Norway.

While the data indicated that graduate-teachers are confident, twelve weeks of field practicum in UTT's B.Ed. programme cannot justifiably prepare them for the complexity of the real classroom, as they were pre- service teachers with no previous teaching experience. Smith \& Lev-Ari (2005) found that, "Students rated the practicum highly as the main source of most aspects of teachers' professional knowledge" (p. 295). A period of induction is suggested to aid graduate-teachers to grapple with the demands of the uniqueness of their individual classes. One participant concurred, "I believe that a period of internship in the final year may better prepare the teacher for the classroom. At least, the student teachers will have the opportunity to experience the reality of the classroom". Internal professional development seminars, webinars, and online networks with best practices for sharing experiences and successes may be beneficial. A participant indicated, "The teacher support must start within the school itself and not just from the Ministry of Education. Principals must be trained so that they could recognize the expertise and talent in members of staff", while another intimated, "I suggest the formation of a learning community in every school". National workshops with practical applications for inclusivity, diversity and emerging disciplinary problems should be conducted.

Although courses in crisis management, preparation for natural disasters, conflict management or counselling could be addressed at higher education institutions, it must be noted that it is almost impossible to be prepared for every eventuality of the classroom as problems evolve continuously. Also, within the context of a global society, new emerging problems are likely to escalate. In addition, students are bombarded by media and social media which may influence their behaviours adversely. The emanating issues may not necessarily be anticipated and therefore the impact on students may not be ameliorated by educational institutions. Therefore, the onus is on graduate-teachers to engage in reflective practice, to be proactive, and creative in solving the problems in their individual classes. Consultation with Heads of Departments, Vice Principals and Principals are readily available and students may be referred to Student Support Services (MOE).

This research has implications for programme accountability, the review of the B.Ed. programme offered at UTT and other corresponding programmes, to suit the demands of the real classroom. Titus (2013) suggests a shift from "knowledge for practice" . . . to . . . "knowledge of practice"(p. 13). Systems need to be implemented to address the concerns of graduate-teachers and the myriad challenges they face, especially with regard to classroom management. Perhaps a period of induction for one year whereby graduate-teachers are mentored by experienced teachers may be a possible solution to the problem.

\section{CONCLuSion}

Perhaps the quality and quantity of simulations, in-house and field practice, evaluation of relevant videos, small group tutorials and micro-teaching need to be revised to address the dilemmas, 
particularly classroom management. In his study Goodwin (2012) concurred that teachers identified dealing with students' behavior as a major problem. Emphasis must also be placed on culturally relevant pedagogy, classroom management competencies and possible interventions.

The study informs policy decision making and suggests that changes should be made to UTT's B.Ed. programme, and by extension other similar programmes, on a regular basis to make teacher preparation more functional for the complex actualities of the real classroom. Commentators have argued that teaching is an ever-changing, dynamic profession that requires teachers to embrace consistent challenges in the real classroom. Self-study and ongoing independent learning are therefore advocated for effective teaching. An issue for consideration is whether a programme of licensure should be instituted to ensure that graduate-teachers meet the needs of the real classroom.

\section{REFERENCES}

[1] Ball, D. (2000). "Bridging practices - intertwining content and pedagogy in teaching and learning to teach", Journal of Teacher Education, 51(3), 241-247.

[2] Cochran-Smith, M., \& Lytle, L.S. (1999). "Relationships of knowledge and practice: Teacher learning in communities." Review of Educational Research in Education, 24, 249-305.

[3] Cohen, L., Manion, L., \& Morrison, K. (2011). Research methods in education. New York, NY: Routledge,

[4] Creswell, J. W. (2012). Educational research: Planning, conducting and evaluating quantitative and quail tative research (4th ed.), Upper Saddle River, NJ: Pearson.

[5] Goodwin, B. (2012). "Supporting beginning teachers", Educational Leadership, 69 (8), 84- 85. Retrieved 29.5.17 from http://www.ascd.org/publications/educational-leadership/may12/vol69/num08/NewTeachers-Face-Three-Common-Challenges.aspx

[6] Johnson, R. B., \& Onwuegbuzie, A. J. (2004). "Mixed methods research: A research paradigm whose time has come", Educational Researcher, 33 (7), 14-26.

[7] Knowles, M. S., Holton, E. G., \& Swanson, R. A.(2005). The Adult Learner (6 ${ }^{\text {th }}$ Edition). New York, Elsevier.

[8] Lichtman, M. (2006). Qualitative research in education. A user's guide, Thousand Oaks, CA: Sage.

[9] Miles, M. B., Huberman, M. A., \& Saldana, J. (2014). Qualitative data analysis. A methods sourcebook (3rd ed.). Beverly Hills, CA: Sage.

[10] Schön, D. A. (1987). Educating the reflective practitioner. Jossey-Bass, San Francisco, CA, 1987.

[11] Smith, K., \& Lev-Ari, L. (2005). "The place of the practicum in pre-service teacher education: the voice of the students", Asia-Pacific Journal of Teacher Education, 33 (3), 289-302.

[12] Titus, N.E. (2013). “A review of literature investigating co-teaching influences in teacher Education Programs", Pennsylvania Teacher Educator, 12, 11-23.

[13] Wikan, G. \& Bugge, L.S. (2014). "Student performance in teacher education in Norway: the impact of student, institutional and structural factors", European Journal of Teacher Education, 37 (4), 442-452. http://dx.doi.org/10.1080/02619768.2014.912626

[14] Yin, R. K. (2016). Qualitative research from start to finish. New York, NY. Guilford Press.

[15] Yost, D. S., Sentner, S., Forlenza- Bailey, A. (2000). "An examination of the construct of critical reflection: Implications for Teacher Education programming in the 21st century", Journal of Teacher Education, 5(1), 39-48.

[16] Zmuda, A., Kuklis, R., \&Kline, E. (2004). Transforming Schools: Creating a Culture of Continuous Improvement. ASCD, Alexandria, Virginia, USA.

Citation: Ms Marlene Thomas and Dr. Leela Ramsook, "Preparedness of Graduate-Teachers from the University of Trinidad and Tobago for the Real Classroom." International Journal of Humanities Social Sciences and Education (IJHSSE), vol 4, no. 10, 2017, pp. 47-53. doi: http://dx.doi.org/10.20431/23490381.0410006 .

Copyright: () 2017 Authors. This is an open-access article distributed under the terms of the Creative Commons Attribution License, which permits unrestricted use, distribution, and reproduction in any medium, 